\section{Oxidative Metabolism in 'Valencia' Sweet Orange (Citrus sinensis Osbeck) Abscission Zone Tissue Treated with the Abscission Agent 5-Chloro- 3-Methyl-4-Nitro-1H-Pyrazole}

\author{
Naveen Kumar ${ }^{1,2}$ and Robert C. Ebel \\ Southwest Florida Research and Education Center, Institute of Food and \\ Agriculture Sciences, University of Florida, Immokalee, FL 34142
}

Additional index words. abscission zone, citrus, flavedo tissue, reactive oxygen species

\begin{abstract}
Chloro-3-methyl-4-nitro-1H-pyrazole (CMNP) is an abscission agent, standardized for the mechanical harvesting of late season 'Valencia' sweet oranges in Florida. This work was conducted to investigate the role of CMNP to induce oxidative stress in the abscission zone (AZ) of 'Valencia' sweet orange. Fully mature 'Valencia' sweet orange trees in a commercial grove were sprayed with $2.0 \mathrm{~mm}$ of CMNP. The experiment was repeated three times during the Apr.-May 2013 harvest season. Fruit were harvested at $0,1,2$, and 3 days after $\mathrm{CMNP}$ application. Hydrogen peroxide $\left(\mathrm{H}_{2} \mathrm{O}_{2}\right)$ concentration and malonic dialdehyde (MDA) concentration, as well as superoxide dismutase (SOD), ascorbate peroxidase (APOD), glutathione reductase (GR), peroxidase (POD), and lipoxygenase (LOX) specific activities were measured $0,1,2$, and 3 days after CMNP treatment (DAT). Rate of lipid peroxidation remains unchanged throughout the abscission period. However, LOX activity increased $1 \mathrm{DAT}$ in $\mathrm{AZ}$ of treated fruit, which might produce jasmonic acid (JA), known to promote abscission in citrus. Levels of $\mathrm{H}_{2} \mathrm{O}_{2}$ were similar in the $A Z$ of control and treated fruit except at 3 DAT. The specific activity of SOD declined at 2 DAT, which showed compromised SOD defense against superoxide radicals $\left(\mathrm{O}^{-}\right)$. APOD activity declined sharply at 3 DAT. Interestingly, GR activity was 1.9-fold higher in CMNP-treated fruit at 3 DAT. Higher GR and low APOD activity reflects limited functioning of the APOD/GR cycle (e.g., APOD and GR) in scavenging of $\mathrm{H}_{2} \mathrm{O}_{2}$ at 3 DAT. Guaiacol POD activity transiently increased at 1 DAT and then declined. POD plays an important role in cell wall lignification and indole acetic acid (IAA) oxidation. The decline in POD activity may cause a decrease in lignification while higher activity made the $\mathrm{AZ}$ sensitive to ethylene and thus promote abscission in citrus fruit. This work also showed that CMNP-induced abscission is a collaborative effort of oxidative metabolism in flavedo tissue (FT) and AZ.
\end{abstract}

Abscission is an active process by which plants shed vegetative and reproductive parts during various developmental stages of their life cycle though a narrow zone of anatomically distinct cells that constitute AZ (Estornell et al., 2013). Besides developmental signals and environmental stresses, commercially available compounds also cause abscission in plant organs (Kossuth et al., 1978; Taylor and Whitelaw, 2001). The peel of citrus fruit consists of the colored outer flavedo and the inner white spongy albedo. However, calyx

Received for publication 23 Oct. 2015. Accepted for publication $20 \mathrm{Feb} .2016$.

We thank E. A. Hanlon (Soil and Water Science Department, SWFREC, IFAS, UF, Immokalee, FL, 34142) for his critical reading of this manuscript. We also thank anonymous reviewers for valuable comments on the manuscript.

${ }^{1}$ Present address: Citrus Research and Education Center, Institute of Food and Agriculture Sciences, University of Florida, 700 Experimental Station Road, Lake Alfred, FL 33850

${ }^{2}$ Corresponding author. E-mail: naveenkumar@ufl. edu.
$\mathrm{AZ}$ is situated deeper within the albedo tissue and could be visually identified (Brown and Burns, 1998).

CMNP is a pyrazole compound and demonstrated as a potential nontoxic abscission agent for the late season 'Valencia' sweet orange crop (Li et al., 2008). It has also been shown to aid in mechanical harvesting of citrus in Florida (Yuan and Burns, 2004). Several studies have been conducted to understand the mechanism of CMNP-induced loosening in mature citrus fruit (Kossuth et al., 1978; Li et al., 2008; Yuan and Burns, 2004). Mechanisms of abscission vary among particular plant parts (Lewis et al., 2006). These studies were focused on CMNP-induced metabolic changes in FT of citrus fruit instead of calyx AZ (Alferez et al., 2005; Alferez et al., 2006; Alferez et al., 2007; Kumar and Ebel, 2015). It has been shown that following CMNP application, there is a gradual decline in chlorophyll content with concomitant rise in total carotenoid in FT of citrus (Alferez et al., 2005). These authors also showed an increase in electrolyte leakage upon CMNP treatment, which suggests membrane degradation could be the possible mechanism for CMNP-induced abscission in citrus (Alferez et al., 2005). It has been proposed that $\mathrm{CMNP}$-induced lipid signaling in FT promotes abscission in calyx AZ (Alferez et al., 2005). CMNP-mediated higher levels of phospholipase A2 (PLA2) and LOX activities were observed in FT (Alferez et al., 2005). However, inhibitory studies using aristolochic acid, which is a potent inhibitor of PLA2 and LOX revealed that lipid signaling partly $(\approx 70 \%)$ accounts for the CMNP-induced abscission (Alferez et al., 2005). This evidence suggests that in addition to lipid signaling, other unknown mechanisms also operate in CMNPmediated abscission process. We showed that other signaling molecules are reactive oxygen species (ROS), such as $\mathrm{O}^{--}, \mathrm{H}_{2} \mathrm{O}_{2}$, and hydroxyl radicals $(\mathrm{OH})$, in CMNP-mediated abscission cascade (Kumar and Ebel, 2015; Sakamoto et al., 2008). Our earlier work on FT showed the generation of $\mathrm{H}_{2} \mathrm{O}_{2}$ at 1 DAT, which is a mobile signaling molecule and has been shown to induce abscission (Kumar and Ebel, 2015; Sakamoto et al., 2008).

Several other pyrazole compounds [pyrazole pyrimidines, pyrazole hydrazone (anticancerous), methyl pyrazole (pesticide), and pyrazolo triazine (herbicides)] also share a common mode of action in treated cells by generating ROS (Graillot et al., 2012; Hassan et al., 2011; Vicentini et al., 2004).

There are reports that showed a direct relationship between ROS and the abscission process (Djanaguiraman et al., 2004; Sakamoto et al., 2008). Sakamoto et al. (2008) observed that $\mathrm{H}_{2} \mathrm{O}_{2}$ is continuously produced by the cell of $\mathrm{AZ}$ in vitro following ethylene exposure. In addition, ethephon-induced abscission was suppressed by inhibitors of $\mathrm{H}_{2} \mathrm{O}_{2}$ in Capsicum baccatum plants (Sakamoto et al., 2008). However, higher activity of antioxidant enzymes has been shown to delay abscission in tomato (Lycopersicon esculentum Mill.) fruit (Djanaguiraman et al., 2004).

The objective of this study was to explore the role of CMNP-induced oxidative metabolism in AZ of 'Valencia' sweet orange [Citrus sinensis (L.) Osbeck] and to understand oxidative association between FT and AZ to further dissect the overall mechanism of abscission. This work provided preliminary data on CMNP-induced $\mathrm{H}_{2} \mathrm{O}_{2}$ changes in $\mathrm{AZ}$ of 'Valencia' sweet orange and also suggests the existence of oxidative cooperation between FT and $\mathrm{AZ}$ to mediate CMNP-induced abscission cascade in citrus.

\section{Materials and Methods}

Plant material and culture. Three independent experiments were conducted on fully mature 15-year-old trees of 'Valencia' sweet orange ( $C$. sinensis Osbeck) scions on 'Carrizo' citrange rootstocks during the Apr.-May 2013 harvest season. The studies were conducted in a commercial grove (Lykes Brothers Inc., Basinger Grove, Lake Placid, FL) that applied standard cultural practices (Li et al., 2008). The trees were spaced $3.7 \mathrm{~m} \times 7.6 \mathrm{~m}$ and were $4.7 \mathrm{~m}$ in height and skirted (height of the lowest branches from soil line) to $0.4 \mathrm{~m}$. 
Treatments. Trees were sprayed using a multihead air-blast sprayer (Model T1000; OXBO International, Clear Lake, WI) with a vertical $(5.5 \mathrm{~m})$ boom oriented parallel to and arched over the outer part of the canopy (Ebel et al., 2010). CMNP was applied at a rate of $2.0 \mathrm{~mm}$ with $0.55 \mathrm{mg} \cdot \mathrm{L}^{-1}$ of Activator 90 as an adjuvant (alkylphenol ethoxylate, alcohol ethoxylate, and tall oil fatty acid or liquid rosin; Loveland products Inc., Greeley, CO). The CMNP applications were made based on air temperatures being $>15.6{ }^{\circ} \mathrm{C}$ with no rain forecast for the first $24 \mathrm{~h}$ after application (Kossuth et al., 1978). Five trees were used for each treatment or as untreated controls at 0,1 , 2, and 3 DAT for estimation of $\mathrm{H}_{2} \mathrm{O}_{2}$ and MDA concentrations as well as LOX, SOD, APOD, and GR activities.

Sampling AZ tissue. The calyx AZ was collected from 40 fruits by using a 4-mmdiameter cork borer. The cork borer was passed through the pedicel and pushed up to the peel (Burns, 2002). The AZ was visually identified in the cylindrical tissue and further trimmed to $6 \mathrm{~mm} \times 4 \mathrm{~mm}$ (Brown and Burns, 1998). These samples were collected in the field and stored in liquid nitrogen at $-80^{\circ} \mathrm{C}$ till further studies.

Measurement of the $\mathrm{H}_{2} \mathrm{O}_{2}$ generation. Each AZ sample [0.5 g fresh weight (FW)] was homogenized in $2 \mathrm{~mL}$ of $0.1 \%$ trichloroacetic acid (TCA) and centrifuged at 12,000 $g_{n}$ for $15 \mathrm{~min}$ at $4{ }^{\circ} \mathrm{C}$. The supernatant $(0.3 \mathrm{~mL})$ was mixed with $1.7 \mathrm{~mL}$ of $1.0 \mathrm{M}$ potassium phosphate buffer, $\mathrm{pH} 7.0$, and $1.0 \mathrm{~mL}$ of $1.0 \mathrm{M}$ potassium iodide solution, and then incubated for $5 \mathrm{~min}$ at room temperature before measuring absorbance at $390 \mathrm{~nm} . \mathrm{H}_{2} \mathrm{O}_{2}$ concentrations were calculated using a standard curve prepared from known concentrations of $\mathrm{H}_{2} \mathrm{O}_{2}$ and were expressed in $\mu \mathrm{mol} \cdot \mathrm{g}^{-1} \mathrm{FW}$ (Velikova et al., 2000).

Measurement of lipid peroxidation. Lipid peroxidation was measured in terms of MDA concentrations using the thiobarbituric acid assay described by Heath and Packer (1968) with slight modifications. Each AZ sample ( $0.5 \mathrm{~g} \mathrm{FW})$ was homogenized in $2 \mathrm{~mL}$ of $0.1 \%$ TCA $(\mathrm{w} / \mathrm{v})$ and centrifuged at $12,000 g_{\mathrm{n}}$ for $30 \mathrm{~min}$. The supernatant $1 \mathrm{~mL}$ was incubated with $2 \mathrm{~mL}$ of $20 \%$ TCA (w/v) containing $0.5 \%(\mathrm{w} / \mathrm{v})$ thiobarbituric acid at $1: 9(\mathrm{v} / \mathrm{v})$ for $30 \mathrm{~min}$ at $95{ }^{\circ} \mathrm{C}$. The reaction was stopped by cooling the test tubes in an ice bath for $10 \mathrm{~min}$ and the contents were then centrifuged at $10,000 g_{\mathrm{n}}$ for $15 \mathrm{~min}$. The absorbance of the supernatant was measured at $532 \mathrm{~nm}$. The value for nonspecific absorption at $600 \mathrm{~nm}$ was subtracted and the amount of MDA-thiobarbituric acid complex was calculated from an extinction coefficient of $155 \mathrm{~mm}^{-1} \cdot \mathrm{cm}^{-1}$. The MDA concentration expressed in $\mu \mathrm{mol} \cdot \mathrm{g}^{-1} \mathrm{FW}$.

Enzyme assays. AZ samples $(0.5 \mathrm{~g} \mathrm{FW})$ were homogenized in $3 \mathrm{~mL}$ of $100 \mathrm{~mm}$ potassium phosphate buffer, $\mathrm{pH} 7.0$, containing $0.5 \mathrm{~mm}$ ethylenediaminetetraaceticacid (EDTA), $0.1 \mathrm{~mm}$ phenylmethylsulfonyl fluoride, $2 \%(\mathrm{w} / \mathrm{v})$ polyvinylpyrrolidone, and $5 \mathrm{~mm}$ ascorbate, using a prechilled mortar and pestle. The homogenate was centrifuged at $4{ }^{\circ} \mathrm{C}$ for $30 \mathrm{~min}$ at $15,000 \mathrm{~g}$. For all enzymatic analyses, the supernatant extract was passed through Sephadex G-25, PD-10 column (Pharmacia, GE Health Care BioScience AB, Uppsala, Sweden) equilibrated with $50 \mathrm{~mm}$ potassium phosphate buffer, $\mathrm{pH}$ 7.0. All enzymes activities were measured in $3 \mathrm{~mL}$ reaction volumes using different aliquots of each supernatant $[25 \mu \mathrm{L}(5 \mu \mathrm{g}$ protein) for SOD, $25 \mu \mathrm{L}$ (5 $\mu \mathrm{g}$ protein) for LOX, $50 \mu \mathrm{L}(10 \mu \mathrm{g}$ protein) for POD, $50 \mu \mathrm{L}$ (10 $\mu \mathrm{g}$ protein) APOD, and $100 \mu \mathrm{L}(20 \mu \mathrm{g}$ protein) for GR].

SOD activity was determined by the method of Dhindsa et al. (1981). Each SOD assay reaction $(3.0 \mathrm{~mL})$ contained $0.2 \mathrm{M}$ methionine, $1.72 \mathrm{~mm}$ nitroblue tetrazolium, an appropriate aliquot $(25 \mu \mathrm{L})$ of the gelfiltered AZ extract, and $0.12 \mathrm{~mm}$ riboflavin in $50 \mathrm{~mm}$ potassium phosphate buffer, $\mathrm{pH}$ 7.8. The riboflavin was added last. The contents of each tube were thoroughly mixed and placed $30 \mathrm{~cm}$ below the two 75-W fluorescent bulbs (Philips, Andover, MA). The reaction was started by switching on the light for $10 \mathrm{~min}$. Each tube was then covered with a black cloth immediately after switching off the light. Nonirradiated reaction mixtures containing the same AZ extract, which did not develop color, were used as controls. A blank reaction without any added $\mathrm{AZ}$ extract produced the maximum blue color. The absorbance of each reaction mixture was read at $560 \mathrm{~nm}$. One unit of SOD activity was defined as the amount of enzyme that caused 50\% inhibition of the initial rate of the reaction in the absence of enzyme (Dhindsa et al., 1981). The specific activity of SOD was expressed in units $\mathrm{min}^{-1} \cdot \mathrm{mg}^{-1}$ total soluble protein (TSP; Bradford, 1976).

APOD activity was assayed in $3 \mathrm{~mL}$ reaction mixtures each containing $50 \mathrm{~mm}$ potassium phosphate buffer, $\mathrm{pH}$ 7.0, 0.1 mM EDTA, $1.0 \mathrm{mM} \mathrm{H}_{2} \mathrm{O}_{2}, 0.25 \mathrm{~mm}$ ascorbic acid, and $50 \mu \mathrm{L}$ of $\mathrm{AZ}$ extract. APOD activity was measured by the rate of oxidation of ascorbate at $290 \mathrm{~nm}$ using extinction coefficient of $2.8 \mathrm{~mm}^{-1} \cdot \mathrm{cm}^{-1}$ (Nakano and Asada, 1981). The specific activity of APOD was expressed in $\mu \mathrm{mol}$ asc. oxidised $\mathrm{min}^{-1} \cdot \mathrm{mg}^{-1} \mathrm{TSP}$.

GR activity was measured in $3 \mathrm{~mL}$ reaction mixture containing $50 \mathrm{~mm}$ potassium phosphate buffer, $\mathrm{pH} 7.5,3 \mathrm{~mm}$ 5,5-dithiobis-2-nitrobenzoic acid, $0.1 \mathrm{~mm}$ EDTA, $2 \mathrm{~mm}$ nicotinamide adenine dinucleotide phosphate, and $100 \mu \mathrm{L}$ of $\mathrm{AZ}$ extract. Each reaction was started by adding $0.67 \mathrm{~mm}$ oxidized glutathione. The increase in absorbance at $412 \mathrm{~nm}$ at $25{ }^{\circ} \mathrm{C}$ was recorded using a period of $5 \mathrm{~min}$ (Smith et al., 1988). The specific activity of GR was expressed in $\Delta A_{412} \mathrm{~min}^{-1} \cdot \mathrm{mg}^{-1}$ TSP.

POD activity was assayed in $3 \mathrm{~mL}$ reaction mixtures containing $50 \mathrm{~mm}$ potassium phosphate buffer, $\mathrm{pH} 7.0,10 \mathrm{~mm} \mathrm{H}_{2} \mathrm{O}_{2}, 0.05 \%$ (v/v) guaiacol, and $50 \mu \mathrm{L}$ of $\mathrm{AZ}$ extract. POD activity was determined by the increase in absorption at $470 \mathrm{~nm}$ due to oxidation of guaiacol using an extinction coefficient of $26.6 \mathrm{~mm}^{-1} \cdot \mathrm{cm}^{-1}$ (Cakmak and Marschner, 1992). The specific activity of POD was expressed in $\mu \mathrm{mol} \mathrm{H}_{2} \mathrm{O}_{2}$ $\mathrm{min}^{-1} \cdot \mathrm{mg}^{-1} \mathrm{TSP}$.

The LOX catalyzed reaction was followed spectrophotometrically by observing the increase in absorbance at $234 \mathrm{~nm}$ arising from conjugated double bonds formed during reaction. AZ samples $(0.5 \mathrm{~g} F W)$ were homogenized in $10 \mathrm{~mL}$ ice cooled $0.1 \mathrm{M}$ potassium phosphate buffer in a prechilled pestle and mortar. The homogenate was allowed to stand for $10 \mathrm{~min}$ at $4{ }^{\circ} \mathrm{C}$ and then centrifuged at $15,000 g_{\mathrm{n}}$ for $30 \mathrm{~min}$ at $4{ }^{\circ} \mathrm{C}$. Supernatant was passed through two layers of muslin cloth to remove fatty layer. The resulting clear supernatant was used as crude enzyme extract for the assay of LOX. The assay mixture composed of $2.975 \mathrm{~mL}$ substrate solution and $25 \mu \mathrm{L}$ of enzyme extract. The reaction mixture was stirred rapidly and increase in absorbance was measured at $234 \mathrm{~nm}$ for $20 \mathrm{~min}$ in 30 -s interval at room temperature (Doderer et al., 1992). The reaction rate was determined from the slope of the straight-line portion of the curve. LOX specific activity was expressed as $\Delta A_{234}$ $\mathrm{min}^{-1} \cdot \mathrm{mg}^{-1}$ TSP.

Total soluble protein. The TSP concentration was determined by the method of Bradford (1976) using bovine serum albumin as standard.

Statistical analysis. Three separate experiments were arranged in a randomized complete block design and five trees were used for each treatment. Each assay was repeated five times on AZ from 45 fruit of each plant. Means values for fruit from each plant were determined and subjected to one-way analysis of variance and separated using the protected least significant difference test using SAS (SAS Institute, Cary, NC) at $P \leq 0.05$. SE of the mean were also calculated.

\section{Results}

$\mathrm{H}_{2} \mathrm{O}_{2}$ concentrations. CMNP treatment increased the formation of $\mathrm{H}_{2} \mathrm{O}_{2}$ in $\mathrm{AZ}$ of fruit at 3 DAT (Fig. 1A). The rise in $\mathrm{H}_{2} \mathrm{O}_{2}$ production was 1.3 -fold in comparison with controls at 3 DAT. However, $\mathrm{H}_{2} \mathrm{O}_{2}$ concentration remained constant $\left(\approx 1.8 \mu \mathrm{mol} \cdot \mathrm{g}^{-1}\right.$ FW) in AZ of control fruit throughout the sampling period.

Lipid peroxidation. The concentrations of MDA were similar in AZ for both of CMNPtreated and control fruit throughout the abscission process (Fig. 1B). The levels of MDA were $\approx 24 \mathrm{nmol} \cdot \mathrm{g}^{-1} \mathrm{FW}$ in $\mathrm{AZ}$ of both control and treated fruit.

SOD activity. SOD specific activity declined severely $(65.0 \%)$ to 2.97 units $\mathrm{min}^{-1} \cdot \mathrm{mg}^{-1}$ protein at 3 DAT from 4.47 units $\mathrm{min}^{-1} \cdot \mathrm{mg}^{-1}$ TSP at 0 DAT in AZ of treated fruit (Fig. 1C). The decline was $75.0 \%$ at 2 DAT. Total SOD activity remained constant $(\approx 4.5$ units $\mathrm{min}^{-1} \cdot \mathrm{mg}^{-1} \mathrm{TSP}$ ) in AZ of control fruit.

$L O X$ activity. LOX specific activity increased at 1 DAT and then transiently declined at $2 \mathrm{DAT}$ in $\mathrm{AZ}$ of treated fruit and thereafter increased (Fig. 2A). Highest LOX specific activity $\left(1.33 \Delta A_{234} \mathrm{~min}^{-1} \cdot \mathrm{mg}^{-1} \mathrm{TSP}\right)$ was observed at $3 \mathrm{DAT}$.

$A P O D$ activity. The changes in APOD specific activity were nonsignificant up to 2 DAT in AZ of CMNP-treated and control fruit (Fig. 2B). Substantial reduction $(50 \%)$ in APOD activity was observed at 3 DAT in 

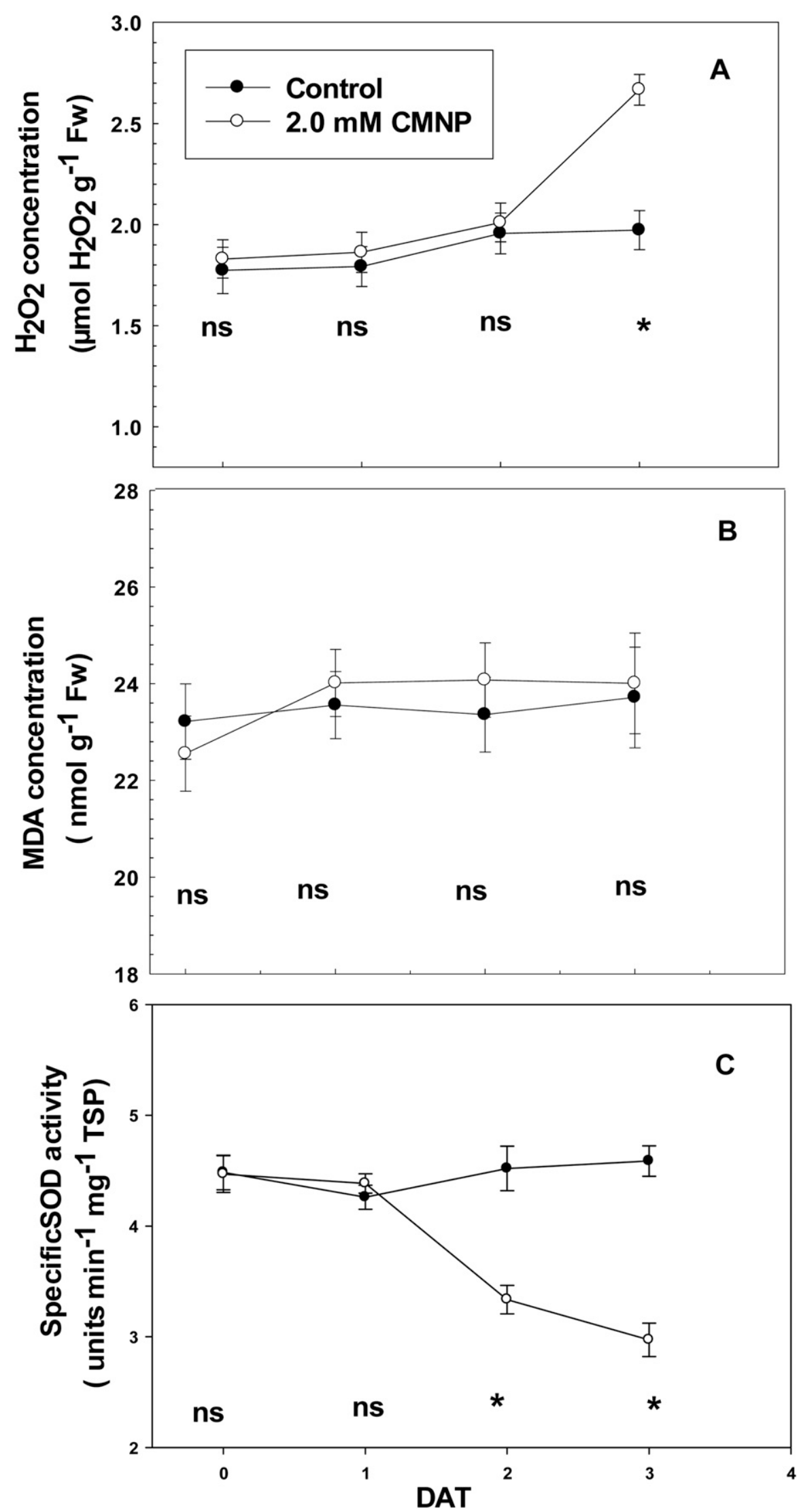

Fig. 1. (A) Hydrogen peroxide $\left(\mathrm{H}_{2} \mathrm{O}_{2}\right)$ concentration $(\mathrm{n}=15)$, (B) malondialdehyde (MDA)concentration $(\mathrm{n}=15),(\mathbf{C})$ specific superoxide dismutase (SOD) activity $(\mathrm{n}=15)$ at various times $(\mathrm{d})$ after a 5-chloro3-methyl-4-nitro-1H-pyrazole (CMNP) spray treatment (DAT) in abscission zone tissue of 'Valencia' sweet orange fruit. Vertical bars represent SE of the mean. Asterisks indicate mean values within each DAT are significantly different from the untreated control values. Mean values were separated using the least significant difference test at $P \leq 0.05$.
AZ of treated fruit. APOD activity in AZ of control fruit was $\approx 0.23 \mu \mathrm{mol}$ asc. $\mathrm{min}^{-1} \cdot \mathrm{mg}^{-1}$ TSP during the abscission period.

GR activity. CMNP enhanced the GR specific activity at successive stages of abscission process (Fig. 2C). The highest GR activity (0.93 $\triangle A_{412} \mathrm{~min}^{-1} \cdot \mathrm{mg}^{-1} \mathrm{TSP}$ ) was observed at 3 DAT. The increase in GR activity was 1.3-fold and 1.6-fold at 1 and 2 DAT, respectively. GR activity in AZ of control fruit remained constant $\left(\approx 0.50 \Delta A_{412} \quad \mathrm{~min}^{-1} \cdot \mathrm{mg}^{-1}\right.$ TSP) at all the stages.

$P O D$ activity. POD specific activity increased transiently at $1 \mathrm{DAT}$ in AZ of treated fruit and thereafter declined (Fig. 2D). The rise in POD activity was 1.3 -fold at 1 DAT. The lowest POD activity was $0.66 \mu \mathrm{mol}$ $\mathrm{H}_{2} \mathrm{O}_{2} \mathrm{~min}^{-1} \cdot \mathrm{mg}^{-1} \mathrm{TSP}$ at 3 DAT.

\section{Discussion}

Several mechanisms have been proposed to elucidate the role of CMNP in citrus abscission. However, most of the investigations were restricted to the FT of fruit (Alferez et al., 2005, 2006, 2007; Kumar and Ebel, 2015). It has been reported that following CMNP treatment, FT generates an unknown lipid signal that facilitates abscission in citrus (Alferez et al., 2005).

Our earlier work showed that in addition to lipid signals, CMNP also causes formation of ROS in FT (Kumar and Ebel, 2015). Herein, we further confirmed the occurrence of oxidative events in AZ tissue of 'Valencia' sweet orange following CMNP application. Progressive decline in fruit detachment force (FDF) was observed following CMNP treatment, which showed the occurrence of cell wall loosening in AZ tissue (Kumar and Ebel, 2015). The decline in FDF was not associated with $\mathrm{H}_{2} \mathrm{O}_{2}$ accumulation in $\mathrm{AZ}$ tissue up to 2 DAT (Fig. 1A). However, it could be mediated by higher levels of $\mathrm{H}_{2} \mathrm{O}_{2}\left(14-16 \mu \mathrm{mol} \cdot \mathrm{g}^{-1}\right.$ FW) in FT (Kumar and Ebel, 2015). We proposed that $\mathrm{CMNP}$ induce a cooperative action between FT and $\mathrm{AZ}$ in terms of $\mathrm{H}_{2} \mathrm{O}_{2}$ generation and SOD activity. Lower accumulation $\left(1.8-2.0 \mu \mathrm{mol} \cdot \mathrm{g}^{-1} \mathrm{FW}\right)$ of $\mathrm{H}_{2} \mathrm{O}_{2}$ between 0 and 2 DAT in AZ was associated with decline $(74 \%$ at 2 DAT and $65 \%$ at 3 DAT) in total SOD specific activity at these stages of abscission (Fig. 1C). However, this decline seems to be complemented by higher SOD specific activity $\left(\approx 10\right.$ units $\mathrm{min}^{-1} \cdot \mathrm{mg}^{-1} \mathrm{TSP}$ at 1-3 DAT) in FT (Kumar and Ebel, 2015). Higher SOD activity produced a copious amount of $\mathrm{H}_{2} \mathrm{O}_{2}$ (1 DAT: $16 \mu \mathrm{mol} \cdot \mathrm{g}^{-1} \mathrm{FW} ; 2$ DAT: $14 \mu \mathrm{mol} \cdot \mathrm{g}^{-1} \mathrm{FW} ; 3$ DAT: $13 \mu \mathrm{mol} \cdot \mathrm{g}^{-1}$ FW) in FT (Kumar and Ebel, 2015). $\mathrm{H}_{2} \mathrm{O}_{2}$ is a mobile signal and can easily diffuse through membranes and maintained up to $16-18 \mu \mathrm{mol} \cdot \mathrm{g}^{-1} \mathrm{FW}$ of $\mathrm{H}_{2} \mathrm{O}_{2}(\mathrm{FT}+\mathrm{AZ})$ in AZ (Kumar and Ebel, 2015; Makino et al., 2004). Alternatively, lower SOD activity in $\mathrm{AZ}$ could increase the production of $\mathrm{O}^{-}$. Free radical-mediated cell wall loosening has been observed during abscission, seed germination, cell elongation, and fruit ripening (Cohen et al., 2015; Fry et al., 2001). In addition, there is a possibility of generation of highly reactive 

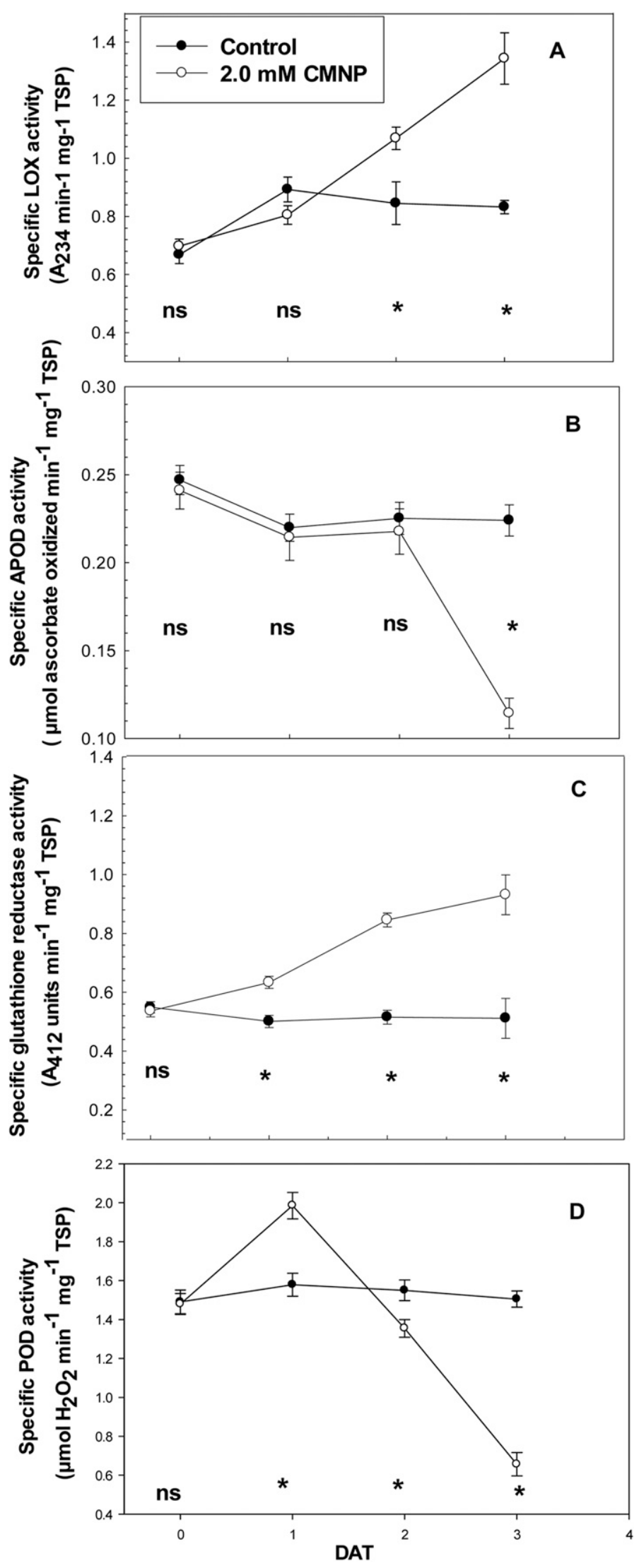

Fig. 2. (A) Specific lipoxygenase (LOX) activity $(\mathrm{n}=15)$, (B) specific ascorbate peroxidase (APOD) activity $(n=15),(\mathbf{C})$ specific glutathione reductase activity $(n=15)$, and (D) specific peroxidase (POD) activity $(\mathrm{n}=15)$ at various times $(\mathrm{d})$ after a 5-chloro-3-methyl-4-nitro-1H-pyrazole (CMNP) spray treatment (DAT) in the abscission zone tissue of 'Valencia' sweet orange fruit. Vertical bars represent SE of the mean. Asterisks indicate mean values within each DAT are significantly different from the untreated control values. Mean values were separated using the least significant difference test at $P \leq$ 0.05 .
$\mathrm{OH}$ in $\mathrm{AZ}$ through the action of PODs (Cohen et al., 2014). PODs are heme-containing enzymes and can generate $\mathrm{OH}^{-}$(Cohen et al., 2014). Higher POD activity was detected in AZ tissue at 1 DAT (Fig. 2D) that could generate $\mathrm{OH}$ via the Fenton reaction. FT derived $\mathrm{H}_{2} \mathrm{O}_{2}\left(16 \mu \mathrm{mol} \cdot \mathrm{g}^{-1} \mathrm{FW}\right)$ might be the substrate for this reaction at 1 DAT (Kumar and Ebel, 2015). The Fenton reaction uses $\mathrm{H}_{2} \mathrm{O}_{2}$ to oxidize the metal ions cuprous $\left(\mathrm{Cu}^{+}\right)$ and ferrous $\left(\mathrm{Fe}^{2+}\right)$, and thus generate $\mathrm{OH}$ in biological systems (Cohen et al., 2014). Hydroxyl radical can directly break or weaken the polysaccharide chains in AZ of longan (Dimocarpus longan Lour.) fruit during carbohydrate starvation (Yang et al., 2015).

CMNP-induced oxidative stress involves the following sequence of characteristic events during abscission: 1) higher levels of $\mathrm{H}_{2} \mathrm{O}_{2}$ in FT can mediate $\mathrm{OH}$ formation in $\mathrm{AZ}$, 2) higher activity of POD at $1 \mathrm{DAT}$ in $\mathrm{AZ}$ tissue can also generate $\mathrm{OH} ; 3$ ) suppression of SOD in $\mathrm{AZ}$ can generate $\mathrm{O}^{-}$, and 4) $\mathrm{H}_{2} \mathrm{O}_{2}$ generation at 3 DAT in AZ can further enhance formation of $\mathrm{OH}$. All these findings suggest the role of ROS in CMNP-induced abscission in citrus.

The levels of MDA concentration remained constant (22-24 nmol. ${ }^{-1} \mathrm{FW}$; Fig. 1C) in AZ in comparison with FT (20-40 nmole. ${ }^{-1} \mathrm{FW}$; Kumar and Ebel, 2015). However, specific LOX activity increased at 2 DAT in AZ that might generate lipid signals or precursor for JA biosynthesis (Fig. 2A; He et al., 2002). It has been well established that early steps in JA biosynthesis are catalyzed by the products of $L O X 1, L O X 2, L O X 3$, and LOX4 genes in Arabidopsis (He et al., 2002). The expression of these genes was several-fold higher during leaf senescence in Arabidopsis thaliana (He et al., 2002). Hartmond et al. (2000) reported that exogenous application of methyl jasmonate $(\mathrm{MJ} ; 10 \mathrm{~mm})$ causes reduction in FDF $(<40 \mathrm{~N})$ in 'Hamlin' and 'Valencia' sweet oranges (C. sinensis Osbeck). MJ application also accelerates production of internal ethylene in these genotypes (Hartmond et al., 2000). However, CMNP application induced 10 times higher production of ethylene in comparison with MJ (U. Hartmond, unpublished data). We suggest that LOX-mediated biosynthesis of JA and subsequent production of ethylene may be a part of CMNP-induced abscission program in AZ tissue.

The pattern of CMNP-induced changes in specific activity of APOD and GR are tissue specific and differ in FT (Kumar and Ebel, 2015) and AZ (Fig. 2B and C). APOD and GR activities declined throughout the abscission in FT but in AZ, APOD activity remained constant up to 2 DAT and then declined by $50 \%$. GR activity profile in AZ responded opposite to FT and showed a rise in specific activity at 1 DAT $(26 \%)$, which further increased up to 3 DAT ( $82 \%)$. APOD-GR cycle regulates cellular redox in plant cells and protects the cell and selected cell organelles from the deleterious effects of $\mathrm{H}_{2} \mathrm{O}_{2}$ (Perl-Treves and Perl, 2002). Low APOD and high GR activity in AZ showed an impaired functioning of APOD-GR cycle, which is responsible for 


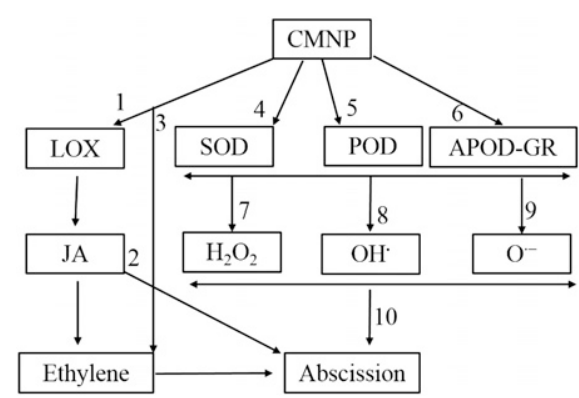

Fig 3. 5-Chloro-3-methyl-4-nitro-1H-pyrazole (CMNP)-induced oxidative changes in abscission zone tissue of 'Valencia' sweet orange: (1) CMNP induced lipoxygenase (LOX) activity can induce synthesis jasmonic acid (JA), which in turn can promote biosynthesis of ethylene and concomitant abscission in citrus (Hartmond et al., 2000), (2) JA can directly accelerate abscission process (Hartmond et al., 2000; $\mathrm{He}$ et al., 2002), (3) CMNP can directly enhance biosynthesis of ethylene in citrus and fruit drop (Burns, 2002; Yuan and Burns, 2004), (4-6) CMNP modify the activity of oxidative enzymes superoxide dismutase (SOD), peroxidase (POD), ascorbate peroxidase (APOD), and glutathione reductase (GR) and causes generation of reactive oxygen species (ROS) including hydrogen peroxide $\left(\mathrm{H}_{2} \mathrm{O}_{2}\right)$, hydroxyl radical $(\mathrm{OH})$, superoxide radical $\left(\mathrm{O}^{-}\right.$; Kumar and Ebel, 2015), and (7-10) ROS can directly induce abscission program (Kumar and Ebel, 2015).

the generation of $\mathrm{H}_{2} \mathrm{O}_{2}$ at 3 DAT in AZ. APOD reduced $\mathrm{H}_{2} \mathrm{O}_{2}$ into water by using reduced ascorbate as an electron donor, which in turn regenerated by the activity of GR via reduced glutathione (GSH; Asada 1999). These results indicate that CMNP promotes accumulation of $\mathrm{H}_{2} \mathrm{O}_{2}$ and oxidative redox in AZ tissue by limiting the APOD-GR cooperative functioning.

Reduced APOD activity can cause accumulation of GSH in AZ, which acts as a substrate for glutathione-S-transferase (GST), chiefly responsible for herbicide or xenobiotic detoxification in plants (Dixon et al., 1998; Licciardello et al., 2014). Several-fold increase in GST gene expression was observed in CMNP-treated A. thaliana leaves (Alferez et al., 2007). There is a possibility that GSH might be used by GST in detoxification of CMNP and its metabolic intermediates in $\mathrm{AZ}$ and thus prevent its translocation to juicy vesicles in fruit.

Plant PODs perform a variety of physiological functions including auxin metabolism, lignin biosynthesis, reactive nitrogen species formation, and ROS metabolism (Almagro et al., 2009; Kumar and Ebel, 2015). CMNPinduced POD profile in AZ is similar to FT and displayed a transient increase in specific activity at 1 DAT and thereafter declined (Fig. 2D; Kumar and Ebel, 2015). This observation showed a collaborative action of POD in FT and $\mathrm{AZ}$ to lower the total concentration of IAA and made the AZ more sensitive to ethylene action (Henry, 1975). PODs also act as IAA oxidases and can cause local decline in IAA levels (Henry, 1975). CMNP has been shown to elevate the levels of ethylene in citrus $(C$. sinensis Osbeck) and concomitant increase in fruit drop (Burns, 2002; Yuan and Burns, 2004).

Our result reflects an oxidative association between FT and AZ to facilitate CMNPinduced abscission in citrus; 1) levels of $\mathrm{H}_{2} \mathrm{O}_{2}$ remained high in FT that might supplement lower levels of $\mathrm{H}_{2} \mathrm{O}_{2}$ up to 2 DAT in AZ to create a highly oxidative environment in $\mathrm{AZ}$ throughout the abscission process (Kumar and Ebel, 2015), 2) impaired APOD-GR cycle in FT and AZ further maintained oxidative redox (Kumar and Ebel, 2015), and 3) complementary higher POD activity in FT and AZ leads to lower levels of IAA (Kumar and Ebel, 2015).

\section{Conclusions}

In summary, CMNP induce a plethora of oxidative events in AZ tissue as described in Fig. 3. We suggest that further experimentation is required to dissect the role of individual ROS in CMNP-induced abscission process in citrus.

\section{Literature Cited}

Alferez, F., L. Pozo, and J.K. Burns. 2006. Physiological changes associated with senescence and abscission in mature citrus fruit induced by 5 chloro-3-methyl-4-nitro- $1 H$-pyrazole and ethephon application. Physiol. Plant. 127:66-73.

Alferez, F., S. Singh, A.L. Umbach, B. Hockema, and J.K. Burns. 2005. Citrus abscission and Arabidopsis plant decline in response to 5-chloro3-methyl-4-nitro- $1 H$-pyrazole are mediated by lipid signaling. Plant Cell Environ. 28:1436-1449.

Alferez, F., G.Y. Zhong, and J.K. Burns. 2007. A citrus abscission agent induces anoxia- and senescence-related gene expression in Arabidopsis. J. Expt. Bot. 58:2451-2462.

Almagro, L., L.V.G. Ros, S. Belchi-Navarro, R. Bru, A.R. Barceló, and M.A. Pedreno. 2009. Class III peroxidases in plant defense reactions. J. Expt. Bot. 60:377-390.

Asada, K. 1999. The water-water cycle in chloroplast: Scavenging active oxygen species and dissipation of excess photons. Annu. Rev. Plant Physiol. Plant Mol. Biol. 50:601-639.

Bradford, M.M. 1976. A rapid and sensitive method for the quantitation of microgram quantities of protein utilizing the principle of protein-dye binding. Anal. Biochem. 72:248-254.

Brown, G.E. and J.K. Burns. 1998. Enhanced activity of abscission enzymes predisposes oranges to invasion by Diplodia natalensis during ethylene degreening. Postharvest Biol. Technol. 14:217-227.

Burns, J.K. 2002. Using molecular biology tools to identify abscission materials for citrus. HortScience 37:459-464.

Cakmak, I. and M. Marschner. 1992. Magnesium deficiency and high light intensity enhance activities of superoxide dismutase, ascorbate peroxidase, and glutathione reductase in bean leaves. Plant Physiol. 98:1222-1227.

Cohen, M.F., S. Gurung, G. Birada, H.-Y.N Holman, and H. Yamasaki. 2015. Bimodal effect of hydrogen peroxide and oxidative events in nitrite-induced rapid root abscission by the water fern Azolla pinnata. Front. Plant Sci. 6(518): 1-8

Cohen, M.F., S. Gurung, J.M. Fukuto, and H. Yamasaki. 2014. Controlled free radical attack in the apoplast: A hypothesis for roles of $\mathrm{O}, \mathrm{N}$, and $\mathrm{S}$ species in regulatory and polysaccharide cleavage events during rapid abscission by Azolla. Plant Sci. 217:120-126.

Dhindsa, R.A., P. Plumb-Dhindsa, and T.A. Thorpe. 1981. Leaf senescence: Correlated with increased permeability and lipid peroxidation and decreased levels of superoxide dismutase and catalase. J. Expt. Bot. 32:93-101.

Dixon, D.P., I. Cummins, D.J. Cole, and R. Edwards. 1998. Glutathione-mediated detoxification system in plants. Curr. Opin. Plant Biol. 1:258-266.

Djanaguiraman, M., D.D. Devi, A.K. Shanker, J.A. Sheeba, and Y.U. Bangarusam. 2004. The role of nitro-phenol on delaying abscission of tomato flowers and fruits. Food Agr. Environ. 2:183-186.

Doderer, A., I. Kokkelink, S. Van Der Veen, B.E. Valk, A.W. Schram, and A.C. Douma. 1992. Purification and characterization of two lipoxygenase isoenzymes from germinating barley. Biochim. Biophys. Acta 1120:97-104

Ebel, R.C., J.K. Burns, K.T. Morgan, and F.M. Roka. 2010. Abscission agent application and canopy shaker frequency effects on mechanical harvest efficiency of sweet orange. HortScience 45:1079-1083.

Estornell, L.H., J. Agusti, P. Merelo, M. Talon, and F.R. Tadeo. 2013. Elucidating mechanisms underlying organ abscission. Plant Sci. 199200:48-60.

Fry, S.C., J.C. Dumville, and J.G. Miller. 2001. Fingerprinting of polysaccharides attacked by hydroxyl radicals in vitro and in the cell walls of ripening pear fruit. Biochem. J. 1(357):729-737.

Graillot, V., F. Tomasetig, J.P. Cravedi, and M. Audebert. 2012. Evidences of the in vitro genotoxicity of methyl-pyrazole pesticides in human cells. Mutat. Res. 748:8-16.

Hartmond, C., R. Yuan, J.K. Bruns, A. Grant, and W.J. Kender. 2000. Citrus fruit abscission induced by methyl-jasmonate. J. Amer. Soc. Hort. Sci. 125:547-552.

Hassan, G.S., H.H. Kadry, S.M. Abou-Seri, M.M. Ali, and A.E. El-Din Mahmoud. 2011. Synthesis and in vitro cytotoxic activity of novel pyrazolo $[3,4-d]$ pyrimidines and related pyrazole hydrazones toward breast adenocarcinoma MCF-7 cell line. Bioorg. Med. Chem. 19:6808-6817.

He, Y., H. Fukushige, D.F. Hildebrand, and S. Gan. 2002. Evidence supporting a role of jasmonic acid in Arabidopsis leaf senescence. Plant Physiol. 128:876-884.

Heath, R.L. and L. Packer. 1968. Photoperoxidation in isolated chloroplasts. I. Kinetics and stoichiometry of fatty acid peroxidation. Arch. Biochem. Biophys. 125:189-198.

Henry, E.W. 1975. Peroxidase in tobacco abscission zone tissue. III. Ultrastructural localization in thylakoids and membrane bound bodies of chloroplast. J. Ultrastruct. Res. 52:289-299.

Kossuth, S.V., R.H. Biggs, and V.M. Winkler. 1978. Uptake and distribution of 14C-labelled 5-chloro-3-methyl-4-nitro-1H-pyrazoe in 'Valencia' and 'Hamlin' oranges. J. Amer. Soc. Hort. Sci. 103:20-22.

Kumar, N. and R.C. Ebel. 2015. Oxidative metabolism in 'Valencia' sweet orange (Citrus sinensis (L.) Osbeck) flavedo tissue treated with the abscission agent 5-chloro-3-methyl4-nitro-1H- pyrazole (CMNP). J. Hort. Sci. Biotechnol. 90(4):413-418.

Lewis, M.W., M.E. Leslie, and S.J. Lijegren. 2006. Plant separation: 50 ways to leave your mother. Curr. Opin. Plant Biol. 9:59-65.

Li, K.-T., J.K. Burns, and J.P. Syvertsen. 2008. Recovery from phytotoxicity after foliar application of fruit-loosening abscission compounds to citrus. J. Amer. Soc. Hort. Sci. 133:535-541. 
Licciardello, C., N. D’agostino, A. Traini, G.R. Recupero, R. Frusciante, and M.L. Chiusano. 2014. Characterization of the glutathione Stransferase gene family through ESTs and expression analyses within common and pigmented cultivars of Citrus sinensis (L.) Osbeck. BMC Plant Biol. 14:39.

Makino, N., K. Sasaki, K. Hashida, and Y.A. Sakkura. 2004. A metabolic model describing the $\mathrm{H}_{2} \mathrm{O}_{2}$ elimination by mammalian cells including $\mathrm{H}_{2} \mathrm{O}_{2}$ permeation through cytoplasmic and peroxisomal membranes: Comparison with experimental data. Biochim. Biophys. Acta 1673:149-159.

Nakano, Y. and K. Asada. 1981. Hydrogen peroxide is scavenged by ascorbate specific peroxidases in spinach chloroplast. Plant Cell Physiol. 22:887-892.
Perl-Treves, R. and A. Perl. 2002. Oxidative stress: An introduction, p. 1-33. In: D. Inze and Van. Montagu (eds.). Oxidative stress in plants. Taylor \& Francis, London, UK.

Sakamoto, M., I. Munemura, R. Tomita, and K. Kobayashi. 2008. Involvement of hydrogen peroxide in leaf abscission signaling, revealed by analysis with an in vitro abscission system in capsicum plants. Plant J. 56:13-27.

Smith, I.K., T.L. Vierheller, and C.A. Thorne 1988. Assay of glutathione reductase in crude tissue homogenates using 5,5'-dithiobis (2nitrobenzoic acid). Anal. Biochem. 175: 408-413.

Taylor, J.E. and C.A. Whitelaw. 2001. Signals in abscission. New Phytol. 151:323-339.

Velikova, V., I. Yordanov, and A. Edreva. 2000. Oxidative stress and some antioxidant systems in acid rain-treated bean plants: Protective roles of exogenous polyamines. Plant Sci. 151:59-66.

Vicentini, C.B., D. Mares, A. Tartari, M. Manfrini, and G. Forlani. 2004. Synthesis of pyrazole derivatives and their evaluations as photosynthetic electron transport inhibitors. J. Agr. Food Chem. 52:1897-1906.

Yang, Z., X. Zhong, Y. Fan, H. Wang, J. Li, and X. Huang. 2015. Burst of reactive oxygen species in pedicle-mediated fruit abscission after carbohydrate supply was cut off in longan (Dimocarpus longan). Front. Plant Sci. 6(360):1-10.

Yuan, R. and J.K. Burns. 2004. Temperature factor affecting the abscission response of mature fruit and leaves to CMN-pyrazole and ethephon in 'Hamlin' oranges. J. Amer. Soc. Hort. Sci. 129:287-293. 